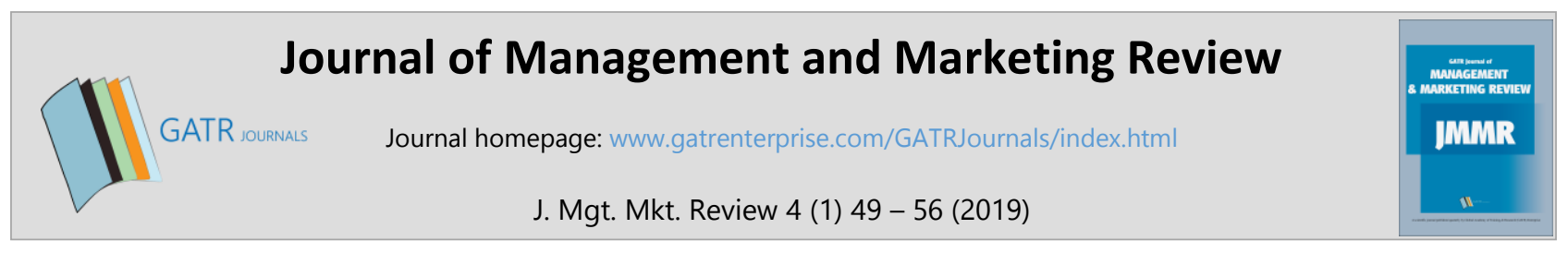

\title{
The Effectiveness of Leadership Training from Generation Me Perspectives
}

\author{
Ihil S.Baron, ${ }^{*}$ Melania, ${ }^{2}$ Hellya Agustina ${ }^{3}$ \\ ${ }^{1,2}$ Lecturer, Sekolah Tinggi Ilmu Ekonomi (STIE) Pancasetia, Jl. Ahmad Yani Km.5,5, 70248, Banjarmasin, South Kalimantan, \\ Indonesia \\ ${ }^{3}$ Ph.D. student, The National University of Malaysia, 43600 UKM Bangi, Selangor Darul Ehsan
}

\begin{abstract}
Objective - This study aims to further explore how leadership training processes are perceived by various generations in an organization. In looking at this phenomenon we use the perspective of the Me generation who are currently attending a wide range of leadership training organized by their own organization as well as outside of the organization. It is expected that this understanding will provide an outline of how the process of leadership training can effectively change behaviour, improve competence, and advance individual's careers in the future.

Methodology/Technique - This study uses a qualitative methodology and a case study with exploratory approach is chosen as the researchers have limited knowledge on the research area. In addition, a case study is a more in-depth study. The procedures of data analysis consist of three actions based on research by Miles and Huberman (1994) that occur instantly: data reduction, data presentation, and conclusion drawing. The findings of this study are a development of skills and expertise which is currently proposed for the security of one's career within an organization.

Findings - With career security, the ability to work is increased and people are not limited to working in the same job. Employees have the opportunity to improve their skills and adapt to their working abilities in a changing environment. This will also improve the company's image, not only from the loyalty of their employees, but also in terms of the achievement of their goal, development of skills, motivation, productivity, and performance.

Novelty - The empirical implications of this study are in line with the trait theory and contingency model. This proposes that a leader must have various attributes to be effective. Effective leadership is characterised by a number of traits such as cognitive abilities, social abilities, and integrated disposition tendencies.
\end{abstract}

Type of Paper: Review.

JEL Classification: M50, M53, M59.

Keywords: Leadership Training Process; Gen-Me Perspectives; Case Study; Exploratory Approach; Career Security; Trait Theory; Contingency Model.

\section{Introduction}

A company must employ human resources professionals with the requisite knowledge, skills and abilities to achieve the expected performance.

\footnotetext{
* Paper Info: Revised: January 18, 2019

Accepted: March 04, 2019

* Corresponding author: Ihil S. Baron

E-mail: ihil.baron@yahoo.com; melaniasjachrani@yahoo.com; p94648@siswa.ukm.edu.my

Affiliation: Sekolah Tinggi Ilmu Ekonomi (STIE), Banjarmasin, South Kalimantan, Indonesia
} 
Technological developments have put pressure on companies to continuously adapt and develop their processes, including their human resources management. For many organisations, change within the organisation can be problematic due to the period of adaptation undergone by their employees. However, the benefits of implementing a strategic human resources plan for dealing with these issues include increasing productivity, stability, and flexibility to adapt to an ever-changing environment. This will also have an impact on employee behaviour.

Campbell, Hoffman and Lance (2010) state that the mix of generations will add valuable diversity to the workforce, complexity and problems for organizations. Not every generation fits within each generational stereotype. Each generation has very different perspective on career development, benefits, and work-life balance. These differences are vital to understanding the changing workplace. The Millennial Generation, or, Generation $\mathrm{Me}$, are typically well-behaved, group-oriented, and anti-individualistic. However, their personalities may grow and change over time. This phenomenon creates psychological differences among generations which has an effect in the workplace. Having regard to this diversity in age groups and the aging demographic (De Long, 2004), managing a multi-generational workforce with different perceptions and goals is extremely challenging in today's multinational organisations (Glass, 2007). However, if managed properly, these differences can be converted into significant strengths and opportunities (Lancaster, Smallman, Tsoukas, \& Van de Ven, 2013).

Generational categories have received increased awareness within organisations (Smola \& Sutton, 2002; Konrad, 2012). Each generation possesses its own values, abilities and characteristics (Burke, 2004), meaning that organisational leaders face many challenges and benefits (Gursoy, Maier, \& Chi, 2008). These generational categories develop trust within their leader-follower relationships and desire to nurture similar relationships under their preferred leadership styles (McNeese-Smith \& Crook, 2003). According to the empirical work by Davenport and Prusak (1998), there is no perfect leadership style; successful leaders are able to adapt their leadership style according to the preference of their subordinates (Shrivastava, Ikonen, \& Savolainen, Winter 2017).

From previous studies, it is assumed that Gen-Me leaders have face an additional challenge arising from the differences between generations; many conflicts occur due to misunderstandings about how to behave and communicate with other generations. Hence, it is important that leaders continue to lead by example when dealing with employees from different age groups.

Employees, or the work force of a company, are the center of any organisation. They are essential for the survival and growth of any company. Hence, every company should place emphasis on the training and development of its employees. Continuous training and development of employees will ensure the sustainability of a company and its continued growth and success. In order to implement the best training methods for employees, organisations should tailor their training packages to the individual employee; this means that each employee from different generations will receive a different training style.

This study aims to address a gap in the research whereby there is a lack of understanding of the best training styles for different generations, and how this affects their work styles.

\section{Literature Review}

Training is as a systematic effort to master the skills, rules, concepts, or ways of behaving that impact on performance (Goldstein \& Gessner, 1988). Furthermore, according to Dearden (1984), training includes teaching and learning, as well as exercises aimed at achieving a certain level of competence or work efficiency. Employees who undergo certain training are expected to possess the requisite skills to which the training relates. In this way, employee training is typically tailored to specific situations or issues. Furthermore, Feldman and Yarbrough in Sudiana (2007) demonstrate that training is a learning effort, organized by firms (government agencies, non-governmental organizations, corporations, etc.) to meet their needs or to achieve organizational goals. Training is "one of the types of learning process to acquire and improve skills beyond the human resource development system, which apply in a relatively short period of 
time with a more tactical method rather than theory". Hence, training can be considered as a process of conveying knowledge, skills, attitudes, and personality development (Sastradipoera, 2006).

Employee training helps an organization to accomplish its objectives, while contributing to the overall development of its employees. Training is usually short-term based on the knowledge, skills, or behaviours that are critical for successful job performance (Swanson \& Holton, 2001; Noe, 2010). The beginning of the $21^{\text {st }}$ century has seen a dramatic increase in the number of people joining the workforce. This is primarily due to globalization and technology exploitation (Allen, 2010) as well as increased competition (Qayyum, Sharif, Ahmad, Khan, \& Rehman, 2012; Kumpikaite \& Sakalas, 2011).

Employees need to be provided with continuous training to align themselves with the organization's mission and vision. Spender (2001) states that employees must obtain a wide range of skills and a broad knowledge in personal as well as professional attributes. On the job training and development was once thought of as an extra effort however, in recent times, it has become essential for all employees (Garner, 2012). Similarly, it is an undeniable fact that in response to changing work practices, if employees are not provided with the chance to increase their professional expertise, they are at risk of skill obsolescence. Skill obsolescence is defined by Greenhause, Callanan and Godshalk (2000) as the absence of sophisticated knowhow and advanced expertise required to accomplish organizational tasks. This has led to organisations, regardless of their size and scope of operations, to focus on competency-based hiring and set challenging job tasks.

To understand this phenomenon, the underlying theory of this study is the trait theory and the contingency model. Trait theory states that leaders are people who are born with the right traits for leadership. This theory can be traced back to the $19^{\text {th }}$ century, when Thomas Carlyle used this theory to identify the talents, skills, and characteristics of men who rose to power. The theory of leadership is based on the characteristics of many leaders - successful and unsuccessful - and is used to predict leadership effectiveness. The list of traits produced is then compared with a list of prospective leaders, to assess the likelihood of their success or failure. Once discovered, this theory states that leaders who are said to have natural talent are individuals who can be nurtured to become great leaders.

Secondly, a comprehensive view of the contingency model according to Fiedler et. al., (1986) proposes that the effective performance of a group of workers is dependent on the match between the style of leadership desired by the subordinates as well as the extent to which the situation allows the leader to control and influence their subordinates. To better understand this theory, previous research conducted by Nebeker and Mitchell (1974) explains the expectancy theory, a further approach, which states that the effectiveness of the task group or organization depends on two main factors, namely: the personality of the leader and the extent to which the situation gives strength, control and influence to the leader. Because personality is relatively stable, even though it can be changed, the contingency models shows that increasing an individuals' effectiveness requires changing the situation to suit the leader. This is often called "job engineering" or "job restructuring". Organizations or leaders can add or reduce the structure of tasks and positions of power, as well as provide training and development to individuals and groups or improving leader-member relations. Fiedler, Chemers and Mahar (1976) state that independent leadership training programs are designed to help leaders learn to change their preferences in a given situation, also known as situational control. As one of the implications of "job engineering" or "job restructuring" described is indeed necessary through additional training with the opinion that if all leaders are given the same training regardless of their position in the contingency model, this may create a mismatch between the leader and the situation.

The book by Fiedler, Chemers and Mahar (1976) states that "the right person for a particular job today may be the wrong person in six months or in a year or two." Hence, it can be said that the contingency model allows leaders to see how the needs of an organization can be changed when one of the dynamics is customizable, things that can indicate a need for new leaders are more suitable, or changes in the situational circumstances to return to a better environment for leaders who are assigned to keep growing. 
Conversely, the researchers also assume that the term behaviour is used in a broad sense of training, covering the knowledge and skills employees acquire through practice or direct experience. The purpose of providing training is to enable the individual to acquire the ability to perform certain tasks or work satisfactorily. It is also said that training and development programs have one or more of the following goals: 1) increasing individual self-awareness; 2) improving individual skills in one or more areas of expertise; 3 ) increasing the motivation of individuals to perform their duties or work satisfactorily; 4) preventing the obsolescence of science and technology skills at all levels within the company; and 5) preparing the worker to perform the task or work at a higher level.

\section{Research Methodology}

This research is a qualitative study using exploratory research. In this exploratory research, a case study method is used. Yin (2015) defines the case study research method as "an empirical inquiry that investigates a contemporary phenomenon within its real-life context; when the boundaries between phenomenon and context are not clearly evident; copes with the technically distinctive situation in which there will be many more variables of interest than data points; in which multiple sources of evidence are used, with data needing to converge in a triangulating fashion; and benefits from the prior development of theoretical propositions to guide data collection and analysis". A case study is also a more in-depth study, as compared to studies with many observations (breadth). In this descriptive case study, the researchers will present a complete description of the phenomena within its context i.e. how the process of leadership training from generation me perspectives can be delivered successfully and effectively.

An in-depth interview technique is used as the primary method of data collection in this case study. A key feature of an in-depth interview is the depth of focus on the individual. It provides an opportunity for detailed investigation of each person's personal perspective, for in-depth understanding of the personal context within which the research phenomenon is located, and for very detailed subject coverage (Ritchie, Lewis, Nicholls, \& Ormston, 2013). Therefore, in this study the researchers investigate each participant's personal perspective and experiences with leadership training within their organization.

Specifying the target population is a crucial aspect of the sampling plan. Meanwhile, a feature of qualitative sampling is often small as a phenomenon only need appear once to be of value. There is no need for scale as there is no need for estimates of statistical significance. Furthermore, because qualitative investigation aims for depth as well as breadth, the analysis of large numbers of in-depth interviews would simply be unmanageable. However, the small-scale approach will only work if the researcher has a strong sampling strategy (Ritchie \& Lewis 2003). The instruments of this study consist of: written form (a brief form that gathers information used to describe the sample, for example, biological sex, age, education, occupation, work experiences) and interview protocol with fourth research questions. We recruited some participants who fall within the Gen-Me generation working in various organisations and attending leadership training. The respondents live in Banjarmasin (South Kalimantan).

According to Huberman and Miles (1994), the process of analysing qualitative data requires three (3) steps: (i) data reduction, (ii) data exposure, and (iii) conclusions and data verification. Generally, data analysis is performed whenever data is collected (with-in-site analysis). This means that the data analysis begins with the data collected from the first participant to avoid a build up of data and information, to make data reduction more efficient. Data reduction involves the process of selecting, focusing, simplifying, removing and transforming what is in the transcript note. In other words, the reduction process involves deleting any data that does not give any meaning to the study or data that does not contribute to the research question.

The reduction process must be done from the beginning of the data collection until all of the data is collected. This process is part of the ongoing process of data analysis. This process ensures that the collected data can be refined, restructured, removed and compiled as a whole to reach the conclusions of the study. Reduced data needs to be re-read to identify patterns, themes, equations or differences. Any data that has 
been reduced is called a unit. From the reduced data, the researchers build codes that are used to illustrate patterns / themes that arise from the data. The code will be defined from the first transcription to facilitate the identification of the themes /patterns that will arise in the second and subsequent transcriptions. To facilitate writing, the data that has been analysed is put into narrative form and a tree diagram, as appropriate, to illustrate the overall phenomenon. Following this, conclusions should be reached and verification of the data should be conducted. Verification ensures the validity and reliability of the data collected. This is to determine the meaning of what has happened and to describe the situation with a complete explanation.

According to Miles and Huberman (1994), codes can be based on the place of the study, the definition of the participants' situation, perspectives/thoughts, processes, activities, events, strategies, social relationships, and theoretical foundations. The coding scheme must be closely linked to the problems studied and related theories. In addition, the categories created should relate to the responses to the issues being studied. The coding scheme must be complete and allow all identified responses to be classified. This means that researchers need to build a comprehensive coding scheme. Based on the guidelines that have been raised, this study uses prefix codes before and during the transcription process that take into account the relevant theories, the research questions and the participants' responses.

\section{Results}

The results of the in-depth interviews with five respondents can be explained as follows. During their work, the respondents have received training and development that is both planned by the human resources (HR) department within their organisations as well as on their own initiatives, to increase their knowledge and improve their skills. Training and development are collectively known as on-the-job training. The training period can last up to six months, depending on the expected time it takes for employees to achieve a satisfactory level of job competency. The form of training and development programs that are attended by employees are very diverse. This program was followed based on the design of the human resources department, from the bottom line, namely lower management, middle management, and to top management. The respondents reported significant changes following their experience in training or development programs. Some of these changes included better relationships with their leaders, more efficient use of time when completing tasks at work and higher levels of enthusiasm when completing work.

In some conditions, new ideas emerge that can make work more effective. However, due to this knowledge, demand of employees will also increase because new targets are also set to increase profits for companies. This is why the cost of training and development can be a concern for companies. However, when the payment for training and development of employees is referred to as an "investment" rather than an "expense", this highlights the benefits of providing further training to staff, as it represents a small investment in order to achieve long-term sustainability of the company.

Further, companies also benefit from their staff participating in training and development programs. One such benefit is the reduction of error by employees who have the appropriate training and know-how to complete their given tasks correctly. In the human resources context, employees who are sufficiently trained in their area of expertise will be better equipped to identify opportunities for expansion in the community, thereby improving the productivity and profit of the company. Other benefits, particularly in the human resources field, include giving employees the confidence and ability to be proactive in their work, without having to wait for instruction from their superiors. It also enables them to work more effectively, which adds long-term value to the company and assists it in achieving its goals.

One of the most positive impacts of employee training is that, approximately 2 months after the training is provided, the achievement of production targets continues to rise to $90 \%$. This statement is based on other conditions (outside of training) that remain stable. The other conditions include: machines, number of workers, work time and salary and wages of employees. Training is needed in particular for new employees in carrying out their new duties. This will assist new employees to recognise and understand their new work environment, knowing what should be done and not done. When something happens that threatens an 
organization, a competent human resources employee with adequate training will be better equipped to avoid these threats. They will also be able to read the situation and determine what needs are expected by the outside community. They can also determine what promotions are needed within the organization in accordance with the competency of its employees at that time.

\section{Discussion}

This research is consistent with previous research on the impact of training and development related to job performance (Tetteh, Sheng, Yong, Narh, \& Sackitey, 2017). Previous research states that human resource management trends throughout the world are dynamically changing. Employers are now more concerned with employee retention. It is suggested that employers must pay more attention to employee training and development in order to keep employees motivated in their work. The main benefit of employees training and development is to enhance the performance of the employees as well as the performance of the organization. Training includes any act that entails growing the skills level and knowledge of an employee so as to perform a specific job. It is clear that employees believe that off-the-job training, technology-based learning and coaching and mentoring are the most significant forms of training and development in terms of increasing productivity, boosting morale and increasing employee retention levels.

This study is associated with the trait theory. To understand the model of leader traits and their effect on leader effectiveness or performance, Zaccaro (2007) proposes a model based on other models of leader traits and leader effectiveness/performance. The leader must have various traits to be an effective leader. Effective leadership is based on a set of traits including cognitive abilities, social abilities, and integrated disposition tendencies. To develop these characteristics, a leader must open themselves up to taking part in various training and self-development programs, such as leadership training, to be a more effective leader.

In addition, the contingency model states that there is no best way to organize a corporation, to lead the organization, or make a decision. Instead, the optimal action depends on the internal and external environment of a company. An effective leader will apply their leadership style to the right situation. In leadership training, leaders will learn multiple sets of leadership behaviours including establishing rapport and interpersonal relationships and showing support and concern for subordinates. They will also learns behaviours relevant to the precise structure of the organisation (i.e., the role assignment, planning, scheduling) to ensure the completion of tasks and achievement of goals. Moreover, when these skills are put into practice by leaders, their subordinates will learn how to accept and respect then as a leader, tasks will run in a more structured way, and they will possess the relevant authority and power.

The practical implication of this include the emergence of skill gaps which are critical for the development of human resources within organizations to continue to penetrate the market. Skill gaps threaten the productivity and competitiveness of an organization. This requires human resource management to develop its professional workforce. In responding to the challenges of the skills gap, HR professionals must develop training programs that are able to overcome these problems. HR professionals need to develop strategies that will ensure superior knowledge, skills and experience in each workforce. This must be adapted to the tasks and competencies of each organisation.

Continuous training and investment in employees will result in numerous benefits for the company. Employee performance will be able to be better measured, to ensure employees are receiving the appropriate amount of remuneration. Further, employee performance can be better monitored and assessed to improve efficiency within the organisation and effectiveness of employees. These processes in turn increase employee motivation and productivity as well as company image.

\section{Conclusion}

Training and development of employees is an important part of every organisation. It is important for employees to ensure that they remain at the forefront of performance within their career and also to ensure 
they are working effectively and efficiently to bring value to their organisation. Conversely, training and development of staff is also important for the organisation. Not only does it improve the performance of its employees, but it also improves its image and consequently, its productivity and profitability.

Training and development, particularly in the technology era, will provide employees with the knowledge and ability to effectively manage and navigate any changes that may occur within the organisation. This is important for the organisation to reduce delay, discomfort and dissatisfaction of employees, which all have an impact on company performance and productivity. This also highlights the importance of training and development for human resources employees, as the employees who assist other employees to navigate issues in the workplace and are also responsible for hiring new employees that are suitable to the organisation. Therefore, it is important that top management, managers, and specialists or generalists, are all committed to providing training and development to all employees. Moreover, when these skills are put into practice by leaders, their subordinates will learn how to accept and respect then as a leader, tasks will run in a more structured way, and they will possess the relevant authority and power. For practical implications, HR professionals need to develop strategies that will ensure superior knowledge, skills and experience are attained in each workforce within an organization.

\section{References}

Chemers, M. M., Fiedler, F. and Mahar, L. (1984). Improving Leadership Effectiveness: The Leader Match Concept. New York, NY: Wiley.

Davenport, T. H. and Prusak, L. (1998). Working Knowledge: How Organizations Manage What They Know. Harvard Business Press.

Dearden, P. (1984). Behaviour and the Natural Environment. In I. Altman and J. F. Wohlwill, Human Behaviour and Environment: Advances in Theory and Research (Vol. 6). New York: Plenum Press.

De Long, D. W. (2004). Lost Knowledge: Confronting the Threat of an Aging Workforce. New York: Oxford University Press.

Fiedler, F. E. (1986) The Contribution of Cognitive Resources to Leadership Performance, Journal of Applied Social Psychology, 16, 532-545.

Gardner, J. W. (1990). On Leadership. New York: The Free Press.

Glass, A. (2007). Understanding Generational Differences for Competitive Success. Industrial and Commercial Training, 39(2), 98-103.

Goldstein, I. L. and Gessner, M. J. (1988, July 1). Training and Development in Work Organizations. International Review of Industrial and Organizational Psychology, 3, 43-72.

Greenhause, J. H., Callanan, G. A. and Godshalk, V. M. (2000). Career Management (3rd ed.). Pennsylvania, USA: Dryden.

Gursoy, D., Maier, T. A. and Chi, C. G. (2008). Generational Differences: An Examination of Work Values and Generational Gaps in the Hospitality Workforce. International Journal of Hospitality Management, 27(2008), 448-458. Howe, N. and Strauss, W. (2000). Millennials Rising: The Next Great Generation. Vintage.

Huberman, A. M. and Miles, M. B. (1994). Data Management and Analysis Methods.

Konrad, A. M. (2012). Leveraging Workplace Diversity in Organizations. Organization Management Journal, 3(3), 164-189.

Kumpikaite, V. and Sakalas, A. (2011). The Model of Human Resource Development System's Evaluation. International Conference on E-business, Management and Economics, 46-50.

Lancaster, A., Smallman, C., Tsoukas, H. and Van de Ven, A. H. (2013). When Generations Collide: Who They Are. Why They Clash. How to Solve the Generational Puzzle at Work. London, UK: HarperCollins.

McNeese-Smith, D. K. and Crook, M. (2003). Nursing Values and a Changing Nurse Workforce. Journal of Nursing Administration, 33(5), 260-270.

Nebeker, D. M. and Mitchell, T. R. (1974). Leader Behavior: An Expectancy Theory Approach. Organizational Behavior and Human Performance, 11(3), 355-367.

Noe, R. A. (2010). Employee Training and Development. New York: McGraw-Hill. 
Qayyum, A., Sharif, M. T., Ahmad, A., Khan, M. S. and Rehman, K. U. (2012). Training and Development Practices in National Bank of Pakistan. Information Management and Business Review, 8-17.

Ritchie, J., Lewis, J., Nicholls, C. M. and Ormston, R. (Eds.). (2013). Qualitative Research Practice: A Guide for Social Science Students and Researchers. Sage.

Sastradipoera, K. (2006). Culture-based Resource Development Strategy. Bandung: Kappa Sigma.

Smola, K. W. and Sutton, C. D. (2002). Generational Differences: Revisiting Generational Work Values for the New Millennium. Journal of Organizational Behaviour, 23, 363-382.

Shrivastava, P., Ikonen, M. and Savolainen, T. (Winter 2017). Trust, Leadership Style, and Generational Differences at Work - A Qualitative Study of a Three-generation Workforce from Two Countries. NJB, 66(4), 257-276.

Spender, C. J. (2001). Knowledge Management, Uncertainty, and the Emergent Theory of the Firm. In N. Bontis and C. Choo, the Strategic Management of Intellectual Capital and Organizational Knowledge. London: Oxford University Press.

Sudiana, D. (2007). Conditions for Vocational Middle Stress and the Causes of the Factors. Bandung: Universitas Pendidikan Indonesia.

Swanson, R. A., \& Holton, E. F. (2001). Foundations of human resource development. San Francisco: Berrett-Koehler.

Twenge, J. M., Campbell, S. M., Hoffman, B. J., \& Lance, C. E. (2010). Generational differences in work values: Leisure and extrinsic values increasing, social and intrinsic values decreasing. Journal of management, 36(5), 11171142 .

Yin, R. K. (2015). Qualitative research from start to finish. Guilford Publications.

Zaccaro, S. J. (2007). Trait-based perspectives of leadership. American psychologist, 62(1), 6. 